\title{
Polyp bail-out by the coral Astroides calycularis (Scleractinia, Dendrophylliidae)
}

Eduard Serrano $^{1}$, Rafel Coma ${ }^{1}$, Karina Inostroza $^{2}$, Oscar Serrano $^{3}$

${ }^{1}$ Centre d'Estudis Avançats de Blanes (CEAB-CSIC). Accés Sant Francesc 14, 17300 Blanes, Spain.

${ }^{2}$ BMT Oceanica Pty Ltd, PO Box 462, Wembley, WA, Australia.

3 School of Science, Centre for Marine Ecosystems Research, Edith Cowan University, 6027 Joondalup, Western Australia.

*Corresponding author: eserrano@ceab.csic.es

Telephone: +34972336101

Fax: +34 972337806

Keywords: asexual reproduction, stress, global change, azooxanthellate coral, Mediterranean Sea.

\begin{abstract}
Knowledge of reproductive biology is essential for ecological studies on coral population dynamics. The azooxanthellate colonial coral Astroides calycularis is endemic to the western Mediterranean Sea and adjacent Atlantic coasts. Specimens of this species in artificial conditions, an aquarium with enclosed seawater and low food availability, appeared to show an asexual dispersal mechanism. This mechanism consisted of the detachment and release of single, skeletonless polyps from the underlying colony skeleton (i.e., polyp bail-out). While the released free-living polyps regularly showed extended tentacles and most of them survived, they did not show re-attachment to the substrate or any skeleton formation until the end of the experiment, $2-3$ months after bail-out. Formation of new reproductive colonies, thereby the eventual completion of asexual reproduction through polyp bail-out in A. calycularis, still needs to be confirmed. In addition to sexual reproduction, polyp bail-out may constitute an alternative propagation mechanism during periods of environmental stress, thereby potentially increasing the survival rate of the parental genotype and the dispersal by drifting soft polyps.
\end{abstract}




\section{Introduction}

Knowledge of reproductive biology and its plasticity in scleractinian corals under disturbances is essential for understanding their population dynamics and dispersal. The life cycle of corals involves a dominant benthic polyp phase characterized by the growth of soft tissue and skeleton, and repeated cycles of sexual reproduction that enable genetic recombination and a dispersive larval stage. Although sexual reproduction is the dominant form of reproduction in corals, asexual reproduction is generally common. Asexual reproduction can result from asexual budding of polyps leading to the formation of coral colonies, and/or the production of physically separate a nd dispersive propagules (reviewed by Harrison 2011).

Astroides calycularis (Pallas, 1766) (Scleractinia, Dendrophylliidae) is an azooxanthellate colonial coral with a calcium carbonate skeleton, characterized by the bright orange colour of its polyps and coenosarc (Goffredo et al. 2011; Figs. 1 and 2). The genus Astroides is monotypic and phylogenetically most closely related to Tubastraea, which also consists of azooxanthellate corals (Arrigoni et al. 2014). It is endemic to the western Mediterranean Sea and adjacent Atlantic coasts of Spain and Morocco (Zibrowius 1995; Bianchi 2007; Terrón-Sigler et al. 2016a). The species is generally abundant in shaded habitats exposed to strong currents (i.e., vertical walls and overhangs) from the intertidal fringe to 40 -m depth, with a contagious distribution (Zibrowius 1995; Kružić et al. 2002; Grubelić et al. 2004). Its colonies usually have a massive-shaped morphology with densely crowded polyps in habitats exposed to high hydrodynamic energy, whereas those in relatively deeper or sheltered habitats are generally bush-shaped with separated polyps (Kružić et al. 2002; Goffredo et al. 2011; Casado-Amezúa et al. 2013). Astroides calycularis is catalogued as 'vulnerable' under different national and international legislative schemes (Templado et al. 2004) due to its limited geographic distribution and direct human- and climate-related impacts (Zibrowius 1995; Moreno et al. 2008; Gambi et al. 2010; Movilla et al. 2016).

Astroides calycularis reproduces sexually via tentacular release of brooded planulae (Goffredo et al. 2010; Pellón and Badalamenti 2016). The dispersal capacity of A. calycularis is expected to be low because of the negative buoyancy and demersal behaviour of its planula larvae (Goffredo et al. 2010). Low dispersal capability is also supported by the high levels of genetic connectivity found among coral populations separated by $<1 \mathrm{~km}$, and the genetic differentiation among more distant populations (Casado-Amezúa et al. 2012). Here, we report the first observation of an asexual dispersal mechanism in A. calycularis: 'polyp bail-out' involving the detachment and release of single, skeletonless polyps from the underlying colony skeleton in aquarium conditions. 


\section{Material and Methods}

In December 2012, A. calycularis corals were sampled at Escombreras Island, Cartagena $\left(37^{\circ} 33^{\prime} \mathrm{N}, 0^{\circ} 58^{\prime} \mathrm{W}\right.$; south Balearic Sea, northwest Mediterranean) by SCUBA diving at depths of 8-12 m. Colonies were abundant on vertical walls exposed to high hydrodynamic energy (Fig. 1a) and generally had a massive shape with densely crowded polyps connected by coenosarc (Fig. 1b). After sampling, the coral colonies were placed in large seawater containers and transported to the Experimental Aquarium Zone at the Institute of Marine Sciences in Barcelona. Three colonies ( 4-7 $\mathrm{cm}$ in diameter and with 55-80 polyps) were placed in a separate 100-1 aquarium with enclosed natural seawater and equipped with a circulation pump $\left(900 \mathrm{l} \mathrm{h}^{-1}\right)$. The aquarium was exposed to indirect sunlight and the seawater was not changed over the $\sim 5$-month duration of the experiment. The walls, rocks and sandy substrates in the aquarium were covered by biofilm. The walls were cleaned regularly. Coral colonies were not actively fed, but the seawater likely contained some food resources, such as dissolved and particulate organic matter and micro-organisms (Rosenfeld et al. 1999; Houlbrèque et al. 2004; Houlbrèque and Ferrier-Pagès 2009). During 5-month experimental period, seawater salinity was $\sim 38 \%$ and the temperature gradually increased from $\sim 15$ to $20{ }^{\circ} \mathrm{C}$, simulating the thermal conditions from winter (the sampling period) to spring at the sampling location (Bernardello et al. 2016).

\section{Results}

At the beginning of the experiment, A. calycularis colonies appeared healthy with $<5 \%$ colony partial mortality (Fig. 2a). After approximately 40 days, the colonies started to exhibit partial mortality of the coenosarc leading to dissociation of the polyps from their connective coenosarc and their isolation inside the calyces (Fig. 2b-c). The isolated polyps were observed to actively detach and rele ase from the underlying skeleton $\sim 50$ to 90 days after the start of the experiment (Fig. 2d). All polyps were released after $\sim 90$ days, leaving completely denuded skeletons. The released polyps were slightly negatively buoyant. They were clearly free-living and could easily be lifted from the bottom when manipulated. Examination of the expelled polyps under a stereomicroscope confirmed that they were devoid of calcareous structure but otherwise without morphological anomalies (Fig. 2e). Some of the released free-living polyps were placed on an appropriate substrate for settlement, such as natural rocks with shallow holes (Fig. 2f). Although most released polyps survived ( 90\%) and regularly showed extended tentacles, we did not observe any re-attachment to the substrate by the end of the experiment, $\sim 2-3$ months after bail-out. 


\section{Discussion}

This study extends the current knowledge on the reproductive strategies of the Mediterranean coral A. calycularis by describing for the first time an asexual dispersal mechanism in the species, consisting of the bail-out of single, skeletonless polyps from the underlying colony skeleton. The polyp bail-out in A. calycularis is consistent with the description of this dispersal mechanism in scleractinian corals (sensu Goreau and Goreau 1959; first termed by Sammarco 1982) and proceeded in two steps: (1) isolation of the polyps through the progressive loss of tissue of the coenosarc, and (2) detachment and release of skeletonless single polyps from the underlying skeleton (Fig. 2).

Polyp bail-out was first described by Goreau and Goreau (1959) in some scleractinian species examined during a mesocosm experiment. Further studies have documented this asexual dispersal mechanism in Seriatopora hystrix Dana, 1846 (Sammarco 1982), Pocillopora damicornis (Linnaeus, 1758) (Sin et al. 2012; Kvitt et al. 2015; Shapiro et al. 2016), Acropora tenuis (Dana, 1846) (Yuyama et al. 2012; Kariyazono and Hatta 2015), Cladocora caespitosa (Linnaeus, 1767) (Kružić 2007), and Tubastraea coccinea Lesson, 1829 (Capel et al. 2014). The latter is phylogenetically most closely related to A. calycularis (Arrigoni et al. 2014). In these studies, the release of single polyps devoid of skeleton was associated to an escape response to environmental stress (i.e., enclosed seawater and low food availability in mesocosm experiments, seawater acidification, and thermal, salinity and/or chemical stresses) or biotic interactions (i.e., competition with macroalgae). Kvitt et al. (2015) showed that the process of polyp bail-out in P. damicornis colonies maintained under reduced $\mathrm{pH}$ conditions is controlled by programmed cell death mechanisms in the calicoblastic epidermis. In our study, the unfavourable environmental conditions (e.g., enclosed seawater and low food availability) found in the experimental aquarium could have triggered the polyp bail-out in A. calycularis because food limitation has been shown to play a crucial role in the dynamics of Mediterranean benthic suspension feeders (Coma and Ribes 2003). The seawater temperature range in our experiment ( 15 to $20{ }^{\circ} \mathrm{C}$ ) mimics the natural conditions at the sampling location in Cartagena with an annual thermal regime ranging from 14 to $28{ }^{\circ} \mathrm{C}$ (Bernardello et al. 2016). Indeed, the upper temperature in our experiment was less than the warm sublethal thresholds of $>24-29^{\circ} \mathrm{C}$ described for A. calycularis (Gambi et al. 2010; Movilla et al. 2016). Therefore, despite its cold sublethal thresholds remaining unknown, it seems probable that temperature did not constitute a stress factor in our experiment. In contrast to most previous studies reporting that bailed-out polyps were capable of re-attaching to the substrate and the secretion of a new skeleton, we did not observe re-attachment or skeleton formation in released A. calycularis polyps. This could be partially related to an energy shortage in our experimental aquarium conditions (e.g., enclosed seawater and low food availability) and/or the 
relatively short duration of our experiment after polyp bail-out (i.e., 2-3 months). For instance, reattachment of bailed-out polyps in $T$. coccinea has been documented to take up to 7 months under plankton-fed conditions (Capel et al. 2014).

The polyp bail-out propagation mechanism in scleractinian corals may constitute an alternative form of asexual reproduction and dispersal as survival strategy during periods of environmental stress, allowing released soft polyps to drift away from unfavourable conditions. Although the results of the present study showed that polyp bail-out occur in stressed A. calycularis colonies under extreme aquarium conditions, further investigations are required to confirm whether polyp bail-out also occurs in natural conditions, and whether released polyps could re-attach to the substrate, form a skeleton and generate new reproductive colonies (i.e., to confirm polyp bail-out as a viable form of asexual reproduction). Despite the present experimental setting being far from natural conditions, it seems plausible that human and environmental stressors found in natural con ditions may induce polyp bail out in A. calycularis, for example, in damaged coral colonies commonly found at the base of rocky walls, after detachment from the substrate due to natural causes (e.g., wave action during severe storms) and/or anthropogenic disturbances (e.g., diving activities or fishing gear; Di Franco et al. 2009; Terrón-Sigler et al. 2016b; Musco et al. 2017). Our observations add to the growing records of polyp bail-out within Scleractinia, suggesting that this asexual dispersal mechanism may be more prevalent than previously thought.

\section{Acknowledgments}

We acknowledge the comments provided by four anonymous reviewers. Financial support was provided by the CSI-Coral project (CGL2013-43106-R) from the Spanish Government. OS was supported by an ARC DECRA (DE170101524). ES and RC are part of the Marine Biogeochemistry and Global Change research group from the Generalitat de Catalunya (2014SGR1029).

\section{References}

Arrigoni R, Kitano YF, Stolarski J, Hoeksema BW, Fukami H, Stefani F, Galli P, Montano S, Castoldi E, Benzoni F (2014) A phylogeny reconstruction of the Dendrophylliidae (Cnidaria, Scleractinia) based on molecular and micromorphological criteria, and its ecological implications. Zool Scr 43:661-688 
Bernardello R, Serrano E, Coma R, Ribes M, Bahamon N (2016) A comparison of remote-sensing SST and in situ seawater temperatura in near-shore habitats in the western Mediterranean Sea. Mar Ecol Prog Ser 559:21-34

Bianchi CN (2007) Biodiversity issues for the forthcoming tropical Mediterranean Sea. Hydrobiologia $580: 7-21$

Capel KCC, Migotto AE, Zilberberg C, Kitahara MV (2014) Another tool towards invasion? Polyp “bail-out" in Tubastraea coccinea. Coral Reefs 33:1165

Casado-Amezúa P, Goffredo S, Templado J, Machordom A (2012) Genetic assessment of population structure and connectivity in the threatened Mediterranean coral Astroides calycularis (Scleractinia, Dendrophylliidae) at different spatial scales. Mol Ecol 21:3671-3685

Casado-Amezúa P, Gasparini G, Goffredo S (2013) Phenological and morphological variations in the Mediterranean orange coral Astroides calycularis between two distant localities. Zoology 116:159167

Coma R, Ribes M (2003) Seasonal energetic constraints in Mediterranean benthic suspension feeders: effects at different levels of ecological organization. Oikos 101:205-215

Di Franco A, Milazzo M, Baiata P, Tomasello A, Chemello R (2009) Scuba diver behaviour and its effects on the biota of a Mediterranean marine protected area. Environ Conserv 36:32-40

Gambi MC, Barbieri F, Signorelli S, Saggiomo V (2010) Mortality events along the Campania coast (Tyrrhenian Sea) in summers 2008 and 2009 and relation to thermal conditions. Biol Mar Mediterr $17: 126-127$

Goffredo S, Gasparini G, Marconi G, Putignano MT, Pazzini C, Zaccanti F (2010) Gonochorism and planula brooding in the Mediterranean endemic orange coral Astroides calycularis (Scleractinia: Dendrophylliidae): morphological aspects of gametogenesis and ontogenesis. Mar Biol Res 10:421436

Goffredo S, Caroselli E, Gasparini G, Marconi G, Putignano MT, Pazzini C, Zaccanti F (2011) Colony and polyp biometry and size structure in the orange coral Astroides calycularis (Scleractinia: Dendrophylliidae). Mar Biol Res 7:272-280

Goreau TH, Goreau NI (1959) The physiology of skeleton formation in corals. II. Calcium deposition by hermatypic corals under various conditions in the reef. Biol Bull 117:239-250 
Grubelić I, Antolić B, Despalatović M, Grbec B, Paklar BG (2004) Effect of climatic fluctuations on the distribution of warm-water coral Astroides calycularis in the Adriatic Sea: new records and review. J Mar Biol Assoc UK 84:599-602

Harrison PL (2011) Sexual reproduction of scleractinian corals. In: Dubinsky Z and Stambler N (eds) Coral Reefs: an ecosystem in transition. Springer Netherlands, Dordrecht, pp 59-85

Houlbrèque F, Tambutté E, Richard C, Ferrier-Pagès C (2004) Importance of a micro-diet for scleractinian corals. Mar Ecol Prog Ser 282:151-160

Houlbrèque F, Ferrier-Pagès C (2009) Heterotrophy in tropical scleractinian corals. Biol Rev 84:1-17

Kariyazono ST, Hatta M (2015) Bail-out of the polyp from the skeleton of spats in the scleractinian coral Acropora tenuis. Galaxea J Coral Reef Stud 17:19-20

Kružić P, Zibrowius H, Pozar-Domac A (2002) Actiniaria and Scleractinia (Cnidaria, Anthozoa) from the Adriatic Sea: first records, confirmed occurrences and significant range extensions of certain species. Ital J Zool 69:345-353

Kružić P (2007) Polyp expulsion of the coral Cladocora caespitosa (Anthozoa, Scleractinia) in extreme sea temperature conditions. Nat Croat 16:211-214

Kvitt H, Kramarsky-Winter E, Maor-Landaw K, Zandbank K, Kushmaro A, Rosenfeld H, Fine M, Tchernov D (2015) Breakdown of coral colonial form under reduced $\mathrm{pH}$ conditions is initiated in polyps and mediated through apoptosis. Proc Natl Acad Sci USA 112:2082-2086

Moreno D, de la Linde A, Arroyo MC, López-González PJ (2008) Astroides calycularis (Pallas, 1766). In: Barea-Azcón JM, Ballesteros-Duperón E, Moreno D (eds) Libro rojo de los invertebrados de Andalucía, Tomo 1. Consejería de Medio Ambiente-Junta de Andalucía, Sevilla, pp 281-287

Movilla J, Calvo E, Coma R, Serrano E, López-Sanz À, Pelejero C (2016) Annual response of two Mediterranean azooxanthellate temperate corals to low-pH and high-temperature conditions. Mar Biol 163:135

Musco L, Prada F, D’Anna G, Galasso NM, Pipitone C, Vega Fernández T, Badalamenti F (2017) Turning casualty into opportunity: fragmenting dislodged colonies is effective for restoring reefs of a Mediterranean endemic coral. Ecol Eng 98:206-212 
Pellón J, Badalamenti F (2016) Tentacular release of planulae in Anthozoa: the case of the Mediterranean endemic orange coral Astroides calycularis (Scleractinia: Dendrophylliidae). Coral Reefs 35:1369

Rosenfeld M, Bresler V, Abelson A (1999) Sediment as a possible source of food for corals. Ecol Let $2: 345-348$

Sammarco PW (1982) Polyp bail-out: an escape response to environmental stress and a new means of reproduction in corals. Mar Ecol Prog Ser 10:57-65

Shapiro OH, Kramarsky-Winter E, Gavish AR, Stocker R, Vardi A (2016) A coral-on-a-chip microfluidic platform enabling live-imaging microscopy of reef-building corals. Nat Commun $7: 10860$

Sin LC, Walford J, Goh BPI (2012) The effect of benthic macroalgae on coral settlement. In: Siang TK (ed) Contributions to Marine Science: A commemorative volume celebrating 10 years of research on St John's Island. National University of Singapore, pp 89-93

Templado J, Calvo M, Luque AA, Garvia A, Maldonado M, Moro L (2004) Guía de los invertebrados y peces marinos españoles protegidos por la legislación nacional e internacional. Ministerio de Medio Ambiente, Serie Técnica, Madrid

Terrón-Sigler A, León-Muez D, Peñalver-Duque P, Gálvez-César R, Espinosa Torre F (2016a) Geographic distribution of Astroides calycularis (Scleractinia: Dendrophylliidae) as a baseline to assess future human impacts on the Southern Iberian Peninsula. J Mar Biol Assoc UK 96:1181-1189

Terrón-Sigler A, León-Muez D, Peñalver-Duque P, Espinosa Torre F (2016b) The effects of SCUBA diving on the endemic Mediterranean coral Astroides calycularis. Ocean Coast Manage 122:1-8

Yuyama I, Ito Y, Watanabe T, Hidaka M, Suzuki Y (2012) Differential gene expression in juvenile polyps of the coral Acropora tenuis exposed to thermal and chemical stresses. J Exp Mar Biol Ecol $430-431: 17-24$

Zibrowius H (1995) The "southern" Astroides calycularis in the Pleistocene of the northern Mediterranean-an indicator of climatic change (Cnidaria, Scleractinia). Geobios 28:9-16 


\section{Figure legends}

Fig. 1 Astroides calycularis at Cartagena, south Balearic Sea (northwest Mediterranean). a Coral population dwelling on a vertical wall, and $\mathbf{b}$ massive colony in detail (Photo by Enric Ballesteros)

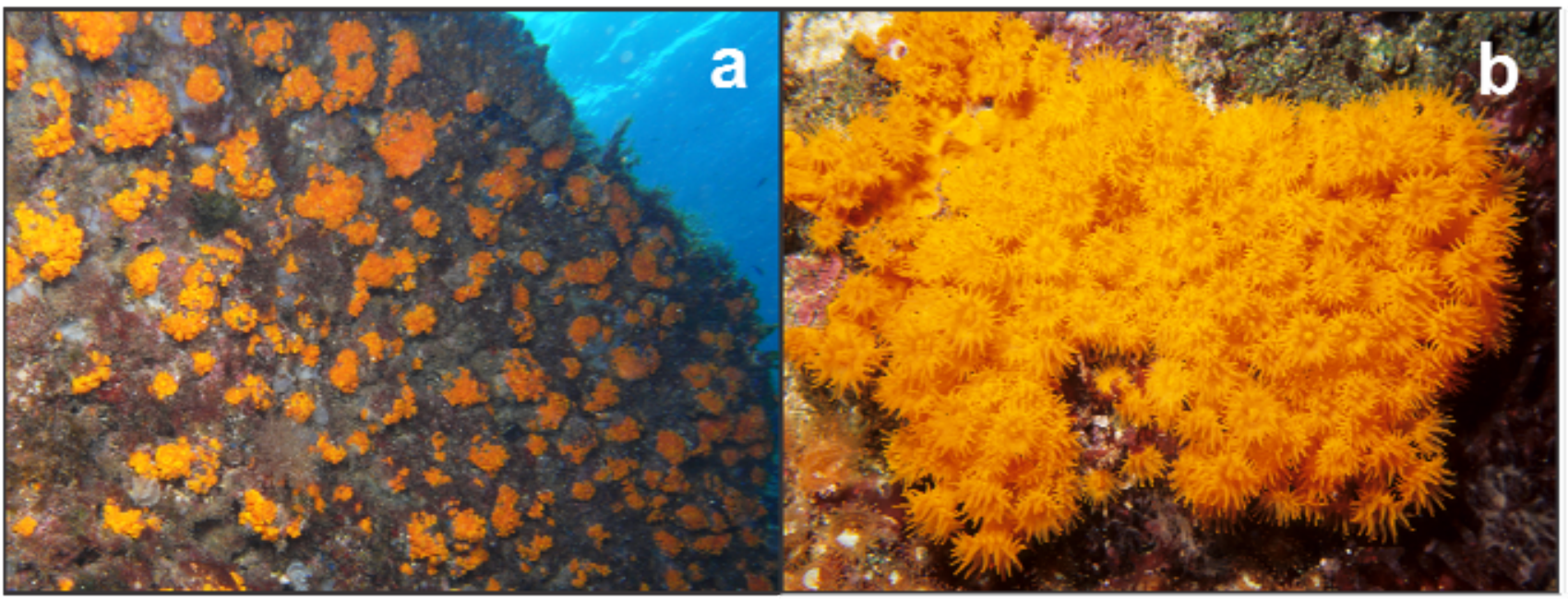

Fig. 2 Polyp bail-out of Astroides calycularis in the aquarium. a Healthy colony with continuous coenosarc. b,c Stressed colony showing isolated polyps ready to detach from the skeleton. d Detachment of a polyp from the skeleton (white arrow). e,f Released polyps

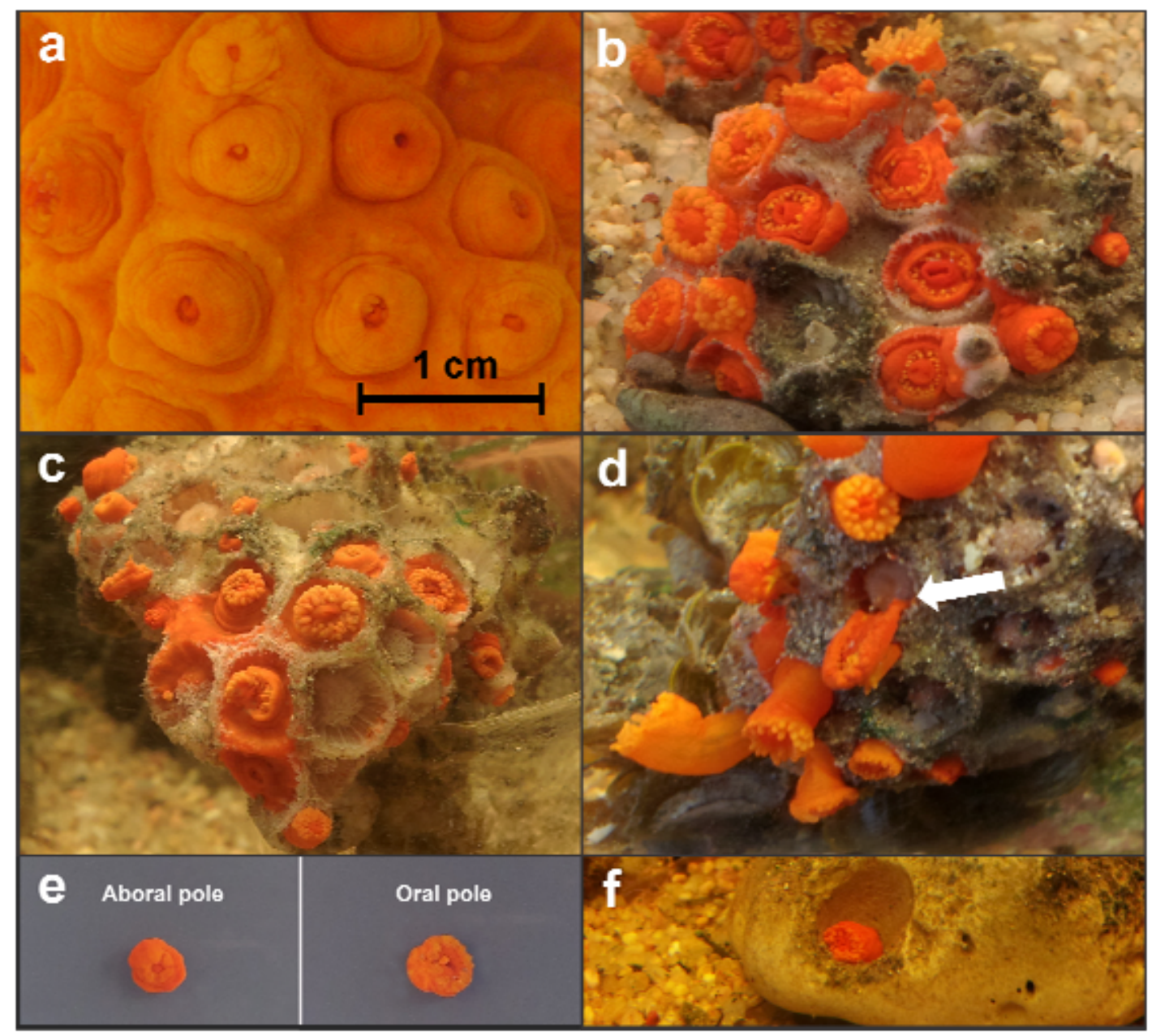

